\title{
Aquilombamento virtual midiático:
}

\section{Uma estratégia metodológica para o estudo das mídias negras}

\section{Aquilombamento virtual mediatic:}

\section{A methodological approach to the study of black media}

\section{Maria do Socorro Furtado Veloso}

Professora associada ao Departamento de Comunicação Social e ao Programa de Pós-Graduação em Estudos da Mídia da Universidade Federal do Rio Grande do Norte. Universidade Federal do Rio Grande do Norte, Programa de Pós-graduação em Estudos da Mídia, Natal (RN), Brasil.

Alice Oliveira de Andrade

Doutoranda do Programa de Pós-graduação em Estudos da Mídia (PPgEM/UFRN) na linha de pesquisa Estudos da Mídia e Práticas Sociais. Bolsista CAPES. Universidade Federal do Rio Grande do Norte, Programa de Pós-graduação em Estudos da Mídia, Natal (RN), Brasil.

\section{Introdução}

"É tempo de formar novos quilombos em qualquer lugar que estejamos. E que venham os dias futuros. [....] A mística quilombola persiste afirmando: a liberdade é uma luta constante". Com esses versos, a escritora negra Conceição Evaristo saudou o ano de 2020, em artigo publicado no jornal O Globoํ.

\footnotetext{
${ }^{1}$ Disponível em: < https://oglobo.globo.com/cultura/em-textos-ineditos-escritores-expressam-desejos-para-2020-1-24165702>. Acesso em: 06 mai. 2020.
} 
Costurando passado e futuro, Evaristo lembra-nos da importância histórica que a união do povo negro representa, independentemente do espaço-tempo que ocupamos.

De tão significativos para a história do Brasil, os quilombos se transformaram em verbo: aquilombar é o ato de se unir para existir não só fisicamente, mas nas demais dimensões do humano. É (re)educar, dialogar, compartilhar, enfrentar, coconstruir. É o corpo individual que se transforma em experiência coletiva de luta, resistência e partilha. Aquilombar é conectar em rede.

Se, em 1580, Zumbi dos Palmares organizou o povo negro em territórios livres; se, nas décadas de 1970 e 1980, o Movimento Negro Unificado (MNU) reuniu militantes em favor da igualdade racial, democrática e de direitos; na contemporaneidade, o aquilombamento precisa seguir como estratégia de sobrevivência do povo negro.

Um exemplo recente e dramático: em meio à crise provocada pela pandemia da Covid-19, que atinge o Brasil desde fevereiro de 2020, dados epidemiológicos da prefeitura de São Paulo constataram que o risco de morte de negros pela doença é $62 \%$ maior em relação aos brancos ${ }^{2}$. A justificativa não está na natureza do vírus, mas na desigualdade social. Sabe-se que falta de saneamento básico, desemprego, dificuldade de acesso à assistência médica e moradia precária aumentam as chances de adoecimento e morte. O extermínio do povo negro por meio da degradação das suas moradias e baixas condições de saúde é historicamente posto (NASCIMENTO, 1978). Por essa razão, o resgate histórico das ações de aquilombamento é fundamental para a resistência negra.

Neste contexto, nos primeiros meses da pandemia, um escritório de advocacia gerenciado por profissionais negros decidiu oferecer orientação virtual gratuita para pessoas negras e periféricas ${ }^{3}$. Um projeto independente monitora os casos de Covid-19 nas favelas do Rio de Janeiro para pressionar o poder público a realizar testagem em massa ${ }^{4}$. Nas redes sociais da internet, pessoas negras evocam outras para a união em "tempos de fim do mundo" ${ }^{5}$. Conceição Evaristo está certa: aquilombar-se é uma necessidade

\footnotetext{
2 Disponível em: < https://saude.estadao.com.br/noticias/geral,em-sp-risco-de-morte-de-negros-por-covid-19-e-62-maior-emrelacao-aos-brancos,70003291431>. Acesso em: 06 mai. 2020.

3 Disponível em: <https://www.almapreta.com/editorias/realidade/advogados-negros-orientam-gratuitamente-vitimas-deracismo-na-pandemia>. Acesso em: 06 mai. 2020.

4 Disponível em: <https://g1.globo.com/rj/rio-de-janeiro/noticia/2020/04/22/voz-das-comunidades-faz-monitoramentoindependente-do-coronavirus-em-favelas-do-rio.ghtml>. Acesso em: 06 mai. 2020.

${ }^{5}$ Disponível em: <https://revistaafirmativa.com.br/cronica-poetica-aquilombar-em-tempos-de-fim-do-mundo/>. Acesso em: 06 mai. 2020.
} 
atemporal. E essa demanda conduz o presente estudo, que tem como objetivo pensar o conceito de aquilombamento virtual midiático como perspectiva metodológica para a compreensão da emergência, das motivações e das condições de funcionamento das chamadas mídias negras no ambiente digital.

Para que seja possível analisar questões étnico-raciais e culturais vinculadas à temática proposta, faz-se necessário desenvolver um diálogo interdisciplinar das ciências da comunicação com áreas do conhecimento afins, como as epistemologias negras. A pesquisa bibliográfica de questões relacionadas à intersecção entre mídia e negritude está embasada nas concepções de Abdias Nascimento (2019), Djamila Ribeiro (2017, 2018, 2019), Achille Mbembe (2014), Sueli Carneiro (2005), Muniz Sodré (2002), Kabengele Munanga (1996) e Beatriz Nascimento (1978), entre outros autores.

\section{Quilombos e aquilombamento}

O sequestro transatlântico de pessoas deixou rastros de dor e sangue. A partir do século XVI, negros africanos de diversas etnias e localidades, como Angola, Moçambique e Guiné, foram forçadamente

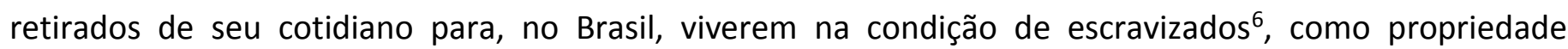
privada de outras pessoas. Não apenas corpos, mas também mentes foram aprisionadas. A sociedade colonial brasileira constituída nessas bases levou a ações de fuga e de organização negra em comunidades autogeridas: os quilombos ${ }^{7}$ (MOURA,1993). Esses modos de sobrevivência marcaram os três séculos de escravização. Após a abolição, em 1888, as comunidades quilombolas se mantiveram e seguiram sobrevivendo da agricultura.

A sociedade escravocrata detinha os corpos negros como objetos. Ao serem trazidos em diáspora, esses indivíduos perderam vínculos com a comunidade, família, religiosidade, cultura, identidade. Por essa razão, é importante ampliar o conceito de quilombo para além da fuga e ocupação de terras, abarcando as relações sociais de pertencimento:

Escravizados, revoltados, organizaram-se para fugir das senzalas e das plantações e ocuparam partes de territórios brasileiros não-povoados, geralmente de acesso difícil. Imitando o modelo africano, eles transformaram esses territórios em espécie de campos de iniciação à resistência, campos esses abertos a todos os oprimidos da sociedade (negros, índios e brancos), prefigurando um modelo de democracia plurirracial que o Brasil ainda está a buscar. (MUNANGA, 1996, p. 63).

\footnotetext{
${ }^{6}$ Neste trabalho, optamos pelo uso do termo escravizados, e não escravos, partindo da ideia de que a escravidão não lhes era inerente, e sim imposta.

${ }^{7}$ A palavra quilombo tem origem etimológica na língua africana bantu, como derivação de kilombo (MUNANGA, 1996).
} 
Historicamente, o aquilombamento é um movimento de luta e resistência do povo negro africano em território brasileiro, também habitado por indígenas e camponeses brancos. No Brasil, os escravizados uniam-se em quilombos, ocupando terras e desenvolvendo atividades de subsistência. A fuga da escravização bárbara fez com que surgissem lógicas sociais pautadas no cultivo da terra e no fortalecimento mútuo. Os quilombos constituíram um esforço dos africanos escravizados em resgatar sua liberdade, dignidade e condições de sobrevivência (NASCIMENTO, 2019).

O quilombo é uma das heranças que os africanos escravizados deixaram para os afro-brasileiros. E não apenas como território físico, mas também como simbologia, ideia, inspiração e sistema de valores combinados para a resistência e formação de uma identidade étnica. Essa identidade, no entanto, é permeada por traços de colonialidade que seguem inferiorizando os corpos negros.

Em 1850, a Lei de Terras proibiu a aquisição de propriedades por meio de posse, permitindo-a somente por meio de compra. Após a abolição, a ordenação jurídica não garantiu a inserção dos negros na sociedade. Por essa razão, os povos escravizados recém-libertos passaram a ocupar precariamente as margens das atividades socioeconômicas, e o aquilombamento seguiu sendo uma possibilidade de sobrevivência.

Essas práticas coloniais, como a Lei de Terras, envolvem mecanismos de controle e dominação sobre os povos colonizados. Sabotar o direito à moradia e propriedade a um grupo já marcado pela lógica da exclusão social foi mais uma tentativa de extermínio daqueles que, após perderem a serventia enquanto mão de obra não remunerada, não mais interessavam à elite escravocrata. Apenas 100 anos depois da promulgação da Lei Áurea, a Constituição Federal de 1988 trouxe, no artigo 68 do Ato das Disposições Constitucionais Transitórias, um indicativo legislativo destinado a garantir o direito desses povos ao território: "Aos remanescentes das comunidades dos quilombos que estejam ocupando suas terras é reconhecida a propriedade definitiva, devendo o Estado emitir-Ihes os títulos respectivos"8.

A agregação do povo negro, portanto, é uma necessidade histórica secular. Aquilombar-se é uma forma de vida que agrega a reconexão com a ancestralidade e o desenvolvimento de ambiências interacionais que propiciem a existência dessas pessoas autonomamente.

\footnotetext{
${ }^{8}$ Disponível em: < http://www.planalto.gov.br/ccivil_03/constituicao/constituicao.htm>. Acesso em: 12 mai. 2020.
} 


\section{Aquilombamento virtual midiático e mídias negras}

"É na luta que a gente se encontra", cantou a Estação Primeira de Mangueira em seu sambaenredo, no carnaval de 2019. O ritmo e a letra do samba ecoaram pelo mundo, especialmente por meio das redes sociais digitais, replicando sua mensagem central: quem luta junto, luta melhor. E a amplitude dessa repercussão está relacionada ao fato de que já não é possível escapar à presença das mídias (SILVERSTONE, 2002).

Ao longo da história do Brasil, no embate contra as lógicas de dominação das elites, indivíduos e grupos negros encontraram nas múltiplas formas de comunicação - como é o caso da música ferramentas basilares para a luta antirracista. Essas insurgências acompanham o acelerado processo de transmutação das mídias, seja enquanto forma de conhecimento ou de prática social. E assim como o acesso às mídias é cada vez mais amplo e popularizado entre as pessoas negras, principalmente devido às tecnologias digitais móveis, a exploração dos potenciais produtivos e disseminadores das redes sociais virtuais também se intensifica.

Esses espaços de invocação dos brasileiros afrodescendentes partem de um objetivo comum, tendo as mídias como ferramentas de construção: o de serem sujeitos protagonistas da própria história e produtores das próprias narrativas. Neste contexto, chama atenção um conjunto de experiências jornalísticas mantidas pelo povo negro no Brasil, cujo objetivo é visibilizar pautas voltadas para a questão racial $^{9}$. Essas narrativas estão organizadas nas chamadas mídias negras, constituídas e operadas por grupos racializados que pensam, produzem e distribuem conteúdos em diversos formatos, interagindo com audiências interessadas nas temáticas abordadas.

Organizados por jornalistas, estudantes de jornalismo e outros atores sociais vinculados à comunicação social, esses coletivos são espaços onde causas e lutas do povo negro mobilizam as agendas (BENTES, 2015). Operam à revelia e muitas vezes em contraponto às corporações midiáticas, e por essa razão podem ser entendidos como contra-hegemônicos (VELOSO, 2014). São mídias marcadas pela multiplicidade de vozes, porque o povo negro é heterogêneo, diverso. Mesmo como experiências localizadas, servem para visibilizar o contexto comum da subjetividade coletiva, gerando produtos

\footnotetext{
${ }^{9}$ A pesquisa doutoral em andamento já localizou 100 iniciativas desse tipo no Brasil (no período de agosto de 2019 a fevereiro de 2020). Incluem-se experiências de ativismo em rede e jornalísticas, que estão em fase de análise.
} 
editoriais que circulam nos meios digitais buscando responder às demandas por informação, mas também por representatividade, desses grupos sociais.

"Precisamos desse exemplo de união legado pela República de Palmares para superar e radicar o racismo e seus duplos": as palavras de Munanga (1996, p. 63) parecem o lema adequado para os objetivos aos quais as mídias negras se propõem. Nessas mídias, os sujeitos são parte das processualidades. Não apenas constroem os discursos disseminados pelos meios, como também inserem nessas narrativas suas subjetividades socioculturais e históricas. Faz-se necessário, por conseguinte, desenvolver uma ferramenta metodológico-interpretativa que possibilite o entendimento dos mecanismos que movem esse fenômeno.

Por se tratar de experiências midiáticas desenvolvidas e dirigidas ao povo negro, interpretá-las à luz do instrumental metodológico tradicional embute o elevado risco de se produzirem análises afetadas pela perspectiva colonial. Acreditamos, portanto, que o mais adequado é fazê-lo por meio de uma articulação que contemple a práxis histórica e social do movimento negro. Por essa razão, propomos o que chamamos de aquilombamento virtual midiático como procedimento para a observação e análise das mídias negras, de seus discursos, lógicas e modos de organização.

Defendemos o aquilombamento virtual midiático como perspectiva metodológica que possibilite aos sujeitos negros a produção de narrativas não subalternizantes sobre o seu povo. A essa demanda estão associados o fortalecimento da luta antirracista; o empoderamento econômico, social e cultural do povo negro; a justiça cognitiva para as epistemologias negras; e igualdade de direitos à existência plena por meio do estabelecimento e/ou valorização de políticas públicas.

Para elaborar a noção de aquilombamento virtual midiático, partimos de três pontos:

1) O conceito de bios virtual (SODRÉ, 2002), que se refere a uma nova esfera existencial formada pela sociedade contemporânea, que caminha no solo informacional, em especial a partir da comunicação eletrônica. Sodré parte do pressuposto aristotélico sobre três esferas (política, dos prazeres e do conhecimento) para defender a existência de um quarto bios, o midiático, virtual. É nessa virtualização do social que enxergamos a possibilidade do aquilombamento virtual midiático.

2) A proposta do quilombismo (NASCIMENTO, 2019), ideia edificadora de um futuro melhor para o povo africano em diáspora a partir da organização coletiva, solidariedade e reinvenção. Abdias 
Nascimento argumenta que "quilombo não significa escravo fugido. Quilombo quer dizer reunião fraterna e livre, solidariedade, convivência, comunhão existencial” (2019, p. 289-290).

3) As reflexões de Beatriz Nascimento (2014) sobre o quilombo como instituição genuinamente revolucionária na história das grandes migrações humanas. Como observa a pesquisadora, quilombos eram espaços de resistência que serviam de fortaleza para os povos negros escravizados resistirem às investidas coloniais de exploração e violência, como foi o caso de Palmares, chefiado por Ganga Zumba (Zumbi dos Palmares). No final do século XIX, passaram a representar um instrumento ideológico contra as diversas formas de opressão, ultrapassando a dimensão física e assumindo a simbologia da união para o fortalecimento dos negros.

Assim, a noção de aquilombamento deixa de ser restrita a uma fortaleza física e expande-se como modo de vida virtualizado (SODRÉ, 2002), como forma de (re)existência em um contexto no qual o racismo é elemento social estruturante, que contribui para tentativas de apagamento histórico e sociocultural das pessoas negras escravizadas e de seus descendentes diretos e indiretos.

Enxergar o aquilombamento virtual midiático como perspectiva metodológico-interpretativa significa partir de uma matriz quilombista para analisar a produção midiática de natureza jornalística (no caso da investigação de doutoramento em curso) feita de e para pessoas negras. Pressupõe recusa a um ângulo colonial ou hegemônico, e a valorização da observação desses fenômenos comunicacionais pelas lentes das lutas antirracistas, antissexistas, antimachistas e contra quaisquer outras formas de desigualdade.

Aquilombar-se é um instrumento eficaz para legitimar o direito à existência e fraternidade dos negros no Brasil. O aquilombamento virtual midiático, por sua vez, é uma ação que opera metodologicamente na práxis da união negra, quando os aparatos digitais servem de instrumento logístico e orgânico para a mobilização.

Aquilombar-se é reconhecer-se. A partir do recorte de iniciativas das mídias negras, que invocam a multiplicidade das narrativas midiáticas no tratamento às questões étnico-raciais, é possível vislumbrar a ação de jornalistas e demais comunicadores que se organizam e se manifestam em rede na tentativa de 
romper com a subalternização de pessoas que cotidianamente sofrem com injustiças sociais e ações de extermínio físico, o que Mbembe (2018) define como necropolítica ${ }^{10}$.

No caso dos coletivos de mídia, apropriando-se de aparatos disponíveis na internet para a produção de conteúdos, pessoas negras engendram espaços contra-hegemônicos para contar histórias comumente silenciadas pela mídia tradicional. Tendo como eixo a luta antirracista, essas experiências são autoorganizadas para estabelecer vínculos de acolhimento, reconstrução histórica, memória, identidade, representatividade, práticas de consumo e sociabilidade por meio da produção midiática, podendo, dessa forma, ser consideradas formas de aquilombamento virtual midiático.

“O modelo quilombista vem atuando como ideia-força, energia que inspira modelos de organização dinâmica desde o século XV", afirma Abdias Nascimento (2019, p. 282). Assim, ao propiciar ambientes de debate, de reivindicações e de reconstruções, as mídias negras visam romper com os grilhões da imprensa hegemônica, que se pauta por uma perspectiva existencial colonialista para a definição de sua agenda e para a construção de narrativas - o que, evidentemente, contribui com diversas formas de apagamento simbólico do povo negro.

Potencializadas pela internet, essas dinâmicas se convertem em estratégias de comunicação e enunciação de causas, desejos, necessidades e desconstruções sociais que precisam ecoar. Ao mesmo tempo, a consciência crítica se impõe na reinterpretação dos discursos midiáticos por parte de pessoas que não se veem neles representadas, impulsionando-as a contestá-los. Para Coutinho (2008, p. 66):

O poder das elites, sua capacidade de determinar o sentido da realidade, de criar e impor significações, ideias, valores aos grupos subalternos, é contrabalançado pela fala popular, com seus códigos estranhos à linguagem hegemônica, seus signos escorregadios, dificilmente assimiláveis e manipuláveis pelo discurso oficial - uma linguagem viva, que se refaz permanentemente no âmbito da comunicação comunitária.

Ao se referir à comunicação comunitária, Coutinho também nos leva a pensar em novos ambientes de resistência no meio digital para a reapropriação e a ressignificação cultural do povo negro. As tradições culturais, religiosas, linguísticas e sociais são formas de resistência identitária incorporadas pelas mídias e amplificadas em múltiplas linguagens. Nesse sentido, Fanon (1983, p. 33) nos lembra de que "falar é existir absolutamente para o outro". Portanto, resume o autor, falar é, além de dominar determinada linguagem morfológica e sintaticamente, assumir o peso de uma civilização e de sua cultura.

\footnotetext{
10 Segundo Mbembe (2018), trata-se do poder e da capacidade de ditar quem pode viver e quem deve morrer, geralmente exercido pelo Estado.
} 
As formas de apagamento simbólicas - questão central nas agendas das mídias negras - são múltiplas. A título de exemplo, as expressões religiosas ilustram como o silenciamento operou no contexto colonial. Negros escravizados foram destituídos do direito de cultuar deuses de matrizes africanas e obrigados ao culto de santos católicos. Atualizadas, as marcas da colonialidade daquele período seguem sequestrando humanidades.

Ainda sobre as lógicas de apagamento simbólico, em dezembro de 1890, Ruy Barbosa, então ministro da Fazenda, ordenou a destruição de documentos relativos ao período da escravidão ${ }^{11}$. Apesar de, como já dito, a história do povo negro não se restringir a esse período histórico, é necessário sublinhar que, no Brasil, a diáspora africana tem relação direta com a exploração física e moral dos habitantes desse continente - e também com seus processos de resistência. Quando o colonialismo apaga esse período da história dos negros, consequentemente os apaga enquanto sujeitos (RIBEIRO, 2018).

Esses exemplos demonstram que a violência é pano de fundo das ações do colonizador. Sejam físicas, simbólicas e/ou cognitivas, as marcas da opressão se fazem presentes sempre que há dominação de um povo sobre os outros. Sob os olhares coloniais, o negro, enquanto ser humano, tem especificidades. Por exemplo: se há literatura negra, há, por outro lado, literatura. O oposto de cinema negro costuma ser lido apenas como cinema. O feminismo negro é enxergado como um recorte do feminismo. Logo, a racialização é um recorte, enquanto o padrão branco é universal. Todavia, o branco também deve ser racializado, e essa compreensão é um aspecto importante para a construção de vias antirracistas para a sociedade.

Diante dessas lógicas de opressão, o desprezo sobre si mesmo faz parte da construção do imaginário social das pessoas negras. Podemos entender as mídias hegemônicas como atravessadoras desse processo quando, cotidianamente, reforçam o lugar do negro nas imagens fixas historicamente criadas, e nas imagens de controle (COLLINS, 2016). Para Collins, imagens de controle são padrões preestabelecidos culturalmente sobre pessoas negras para a reprodução de sexismo, racismo e controle sobre condutas e corpos. Por serem culturais, são dinâmicas e têm como ponto central de combate a autodefinição (BUENO, 2019). As mídias, no desenvolvimento de seus produtos e processos, também podem operar na circulação dessas imagens.

\footnotetext{
11 Disponível em: < http://m.acervo.estadao.com.br/noticias/acervo,a-destruicao-dos-documentos-sobre-a-escravidao,11840,0.htm>. Acesso em: 23 abr. 2020.
} 
As imagens de controle são propagadas de forma tão massiva e constante na mídia por uma razão bastante específica: é confortável para a comunidade branca que existam justificativas que lhes retirem a responsabilidade de responder pelo contínuo de violência que a exploração econômica do povo negro significou na construção do status quo da branquitude. (BUENO, 2019, p.112).

Quando as mídias hegemônicas retroalimentam as imagens de controle (COLLINS, 2016) criadas para mulheres pretas e pardas, prepondera a imagem da negra empregada doméstica, submissa, hipersexualizada ou escravizada. No caso de homens negros, estes costumam ser socialmente vinculados ao estereótipo do criminoso, do malandro, do sujeito perigoso ou objeto sexual. São ideias fixas que desumanizam pessoas negras e tentam reduzir suas existências. Fanon (2008, p. 108) afirma: "quando me amam, dizem que o fazem apesar da minha cor. Quando me detestam, acrescentam que não é pela minha cor". Essa ideia reitera o ciclo sem saída da baixa autoestima que permeia as relações sociais quando se tem a pele escura. Embora a escravidão, em modelo de exploração laboral, tenha terminado há mais de um século, ainda vivemos em uma sociedade de mentalidade escravocrata (SOUZA, 2017), o que causa sofrimento psíquico.

Uma das formas de deslegitimar a população negra é o genocídio, que, segundo Abdias Nascimento (1978), pode ser concreto ou simbólico: vai da morte física em massa da parcela preta e parda da sociedade a estratégias de invisibilização e apagamento da memória. É concreto quando há o massacre de corpos; é simbólico quando se nega o direito à autodefinição. Por essa razão, generalizar é uma das formas de destruição da identidade - e a mídia hegemônica pode ser um dos instrumentos dessas práticas.

O desenvolvimento de estratégias quilombistas deve ser um ponto de reinvenção e mobilização rumo a novas possibilidades de existência dos negros. Por essa razão, também, é que apontamos para a pertinência de se pensarem as mídias negras a partir da ideia de aquilombamento virtual midiático, visto serem resultantes históricas de redes sociais em que ao longo do século vêm operando resistências dos povos afrodescendentes em diáspora.

A semântica do termo "rede" está ligada à ideia de entrelaçamento, conjunto, sistema. Na internet, remete à conexão de pessoas por meio de plataformas digitais. Observar os quilombos nessa perspectiva implica compreender que a ligação, partilha e união de pessoas negras formam estruturas de resistência em redes de pessoas. Esse tipo de conexão tem como matriz a ação político-social coletiva para a transformação, e inspira experiências contemporâneas a reinventar essas ligações. 
Lemos (2013) pontua que o conceito de rede é dinâmico, pois não é necessariamente o que conecta, e sim o resultado dessas ligações. Castells (2013) defende que as redes são operadas pelo ato da comunicação, no sentido da partilha de significados. Isso porque o impacto do desenvolvimento tecnológico, ao longo do tempo, moldou a constituição de novas formas de expressão cultural e das relações sociais, com sociabilidades estabelecidas através das redes (CASTELLS, 1999). Nelas, a contestação do poder fomentou a criação de espaços de autonomia. Castells (2013) define o uso de redes digitais para as ações comunicativas como "autocomunicação de massa":

Nos últimos anos, a mudança fundamental no domínio da comunicação foi a emergência do que chamei de autocomunicação - o uso da internet e das redes sem fio como plataformas da comunicação digital. É comunicação de massa porque processa mensagens de muitos para muitos, com o potencial de alcançar uma multiplicidade de receptores e de se conectar a um número infindável de redes que transmitem informações digitalizadas pela vizinhança ou pelo mundo. É autocomunicação porque a produção da mensagem é decidida de modo autônomo pelo remetente, a designação do receptor é autodirecionada e a recuperação de mensagens das redes de comunicação é autosselecionada (CASTELLS, 2013, p.15).

Nas mídias negras, observamos que a autocomunicação de massa acontece quando atores sociais constroem redes que buscam autonomia e fortalecimento da luta antirracista. Se no aquilombamento histórico as redes eram humanas, no aquilombamento virtual se convertem em conexões digitais com múltiplas expressões. A busca pela transformação, que parte da indignação com o racismo estruturante da sociedade, caminha no sentido de produzir ações político-sociais que respondam às demandas do povo negro. A potência desses movimentos estabelece um fenômeno midiático que pode ser observado metodologicamente pela ótica do aquilombamento virtual, visto que essa ampla constituição de redes perpassa a instrumentalidade técnica para projetar, criar e coconstruir uma alternativa ao anseio de subjetividades individuais e coletivas.

Esses grupos buscam alternativas que permitam ecoar seus anseios e com este intuito juntam-se em blocos, aliam-se a outros movimentos sociais, desenvolvem estratégias midiático-comunicacionais, outras linguagens, ferramentas, enfim, novos modos de se projetarem como sujeitos organizados atentos aos seus direitos (LOPES, 2018, p.22).

Como exemplo, em texto ${ }^{12}$ publicado no Portal Alma Preta, em 30 de abril de 2019, o jornalista Pedro Borges chama atenção para um movimento de integração do povo negro no qual é possível reforçar o direito à existência, pois a jornada coletiva oferece maiores possibilidades de resistir às intempéries:

\footnotetext{
12 Disponível em: < https://www.almapreta.com/editorias/o-quilombo/e-tempo-de-se-aquilombar>. Acesso em: 30 abr. 2020.
} 
O aquilombamento foi uma experiência concreta, que demonstrou na prática que era possível construir uma outra sociedade mais humana, mais justa, mais ambientalmente viável. Os quilombos são o resultado da ousadia, da perspicácia de um povo que não se curvou diante das dificuldades e das barreiras que pareciam intransponíveis. O fim da escravização foi fruto dessa luta. (BORGES, 2019).

Se os quilombos eram unidades radicais de resistência dos povos escravizados que desestabilizavam a lógica escravista e sublinhavam a necessidade de transformações na ordem social (MOURA, 1981), o aquilombamento virtual midiático, a partir de dispositivos digitais de comunicação, torna possível a construção de espaços onde cultura, história, memória e narrativas contemporâneas dos negros são reorganizadas para serem melhor compreendidos. Aquilombar-se virtualmente, portanto, pressupõe a tarefa de descolonização das narrativas midiáticas em prol de uma comunicação antirracista, que atenda às demandas da população negra e reconecte o passado e o presente como uma forma de conceber o futuro.

As experiências jornalísticas insurgentes reunidas nas mídias negras fazem parte de um projeto social democrático que visa, por meio do aquilombamento virtual midiático, contribuir para a ressignificação histórica e sociocultural do povo negro e de suas diferentes demandas. As mídias negras no Brasil atuam em um movimento definido como um conjunto de iniciativas auto-organizadas por pessoas negras que (co)move ${ }^{13}$ outras na construção de uma narrativa antirracista e não colonial sobre o povo negro. Essas experiências, embora diversas, podem ser articuladas em razão das características afins. Consideramo-las como jornalísticas, pois - apesar de, no âmbito do jornalismo, não se enquadrarem em perfis mercadológicos ou comerciais - são práticas sociais, motivadas pela luta contra o racismo, o sexismo, a história única, a dominação, a hegemonia da mídia corporativa em relação à agenda, a exclusão, a invisibilidade e as injustiças sociais e cognitivas do mundo.

Como história única compreende-se, a partir da perspectiva de Adichie (2019), uma narrativa fixa e pejorativa a respeito do povo negro, com base em estereótipos que podem levar à marginalização, invisibilização e anulação dessas pessoas. As mídias negras, enquanto paisagem de disputa, ampliam a possibilidade oposta: de o negro não ser visto apenas como alteridade, e sim como potência de autorreconhecimento e afirmação social de existência.

A atuação das mídias negras nos leva a compreender que, assim como os quilombos foram importantes para a sobrevivência e resistência dos povos negros africanos escravizados, as experiências

${ }^{13}$ O prefixo "co" entra no sentido da ação coletiva. Co-mover é mover coletivamente. 


\section{ALCEU}

ISSN: $2175-7402$

antirracistas na internet são necessárias para que a busca por justiça social seja inclusiva, democrática e global. Para compreendê-las, o aquilombamento virtual midiático pretende apresentar-se como uma perspectiva metodológico-interpretativa que amplia os sentidos diante de um fenômeno que tem raízes antigas, mas busca novas formas operativas.

\section{Considerações finais}

Aquilombar-se é um movimento histórico que toma dimensões contemporâneas a partir do uso de tecnologias digitais e da internet. Carrega a potencialidade de união para construção em coletivo, mas paradoxalmente também traz a ideia essencial da libertação individual e expressão de subjetividades. O aquilombamento desloca pessoas da condição social de assujeitadas e as reinsere na posição de sujeitos da própria organização, mobilização, partilha e comunicação, e por isso pode ser entendido como um instrumento metodológico para a compreensão das mídias negras.

O estabelecimento de vínculos em rede sempre foi uma característica dos quilombos. Primeiro, foram redes sociais físicas e territorializadas que garantiram ao povo negro um espaço de sobrevivência, liberdade e convivência. Em seguida, redes de fortalecimento político nas ruas que visavam a garantia de direitos. Na contemporaneidade, o uso de tecnologias digitais faz com que a resistência negra possa ser operada também em ambientes de redes virtuais, em que um número cada vez maior de pessoas pode se reconhecer, interagir e engajar-se em causas e debates. As mídias negras, na perspectiva quilombista, desterritorializam o sentido dos quilombos quando virtualizam a luta antirracista.

A articulação das bordas sociais em um movimento uníssono, mesmo que diverso, contra o racismo, colocando questões étnico-raciais no centro dos debates, representa uma nova configuração das ações de aquilombamento enquanto estratégia de resistência e existência em uma sociedade estruturalmente racista.

As produções midiáticas hegemônicas, que muitas vezes engendram ideias colonialistas sobre raça, não têm sido suficientes para sanar as lacunas reivindicadas pela luta antirracista. São necessárias pautas disruptivas com o que comumente está posto para fomentar novas experiências que reconfiguram espaços de fala e metodologias de abordagem. Assim, as mídias digitais são ferramenta, mas as práticas midiáticas e a comunicação passam a ser um modus operandi, por si só, de pessoas negras, para que possam existir através do protagonismo cognitivo com narrativas, performances, estéticas. 
Como parte significativa desse caminho, as mídias negras brasileiras articulam a criatividade na reconstrução de narrativas, antes pautadas por estereótipos, e ampliam o campo da luta antirracista e antigenocida. Se, para Abdias Nascimento (2019, p.290), "um futuro de melhor qualidade para a população afro-brasileira só poderá ocorrer pelo esforço enérgico de organização e mobilização coletiva", as mídias negras somam à luta política dos negros brasileiros a ideia de que a comunicação é uma potência para a construção conjunta de uma sociedade mais igualitária e antirracista, e menos colonialista e excludente.

O aquilombamento digital midiático, em síntese, é uma ferramenta operativa encontrada na nuance da práxis, uma vez que intensifica reflexões a respeito das questões cognitivas étnico-raciais, na mesma medida em que atua diretamente no reforço da identidade negra e de sua agência na sociedade.

Maria do Socorro Furtado Veloso

ORCID: https://orcid.org/0000-0002-4515-0737 Universidade Federal do Rio Grande do Norte, Programa de Pós-graduação em Estudos da Mídia, Natal (RN), Brasil. Doutora em Ciências da Comunicação / USP E-mail: socorroveloso@uol.com.br

Alice Oliveira de Andrade

ORCID: https://orcid.org/0000-0002-9048-1893 Universidade Federal do Rio Grande do Norte, Programa de Pós-graduação em Estudos da Mídia, Natal (RN), Brasil. Doutoranda e Mestre em Estudos de Mídia / UFRN E-mail: aliceandrade@live.com

Recebido em: 29 de maio de 2020.

Aprovado em: 22 de fevereiro de 2021.

\section{Referências:}

ADICHIE, Chimamanda Ngozi. O perigo de uma história única. São Paulo: Companhia das Letras, 2019. BENTES, Ivana. Mídia-Multidão: Estéticas da comunicação e biopolíticas. Rio de Janeiro: Mauad X, 2015. 
BORGES, Pedro. É tempo de se aquilombar. Portal Alma Preta, São Paulo, 30 abr. 2019. Editoria O Quilombo. Disponível em: <https://www.almapreta.com/editorias/o-quilombo/e-tempo-de-seaquilombar>. Acesso em: 30 abr. 2020.

BUENO, Winnie de Campos. Processos de resistência e construção de subjetividades no pensamento feminista negro: Uma possibilidade de leitura da obra Black Feminist Thought: Knowledge, Consciousness, And The Politics Of Empowerment (2009) a partir do conceito de imagens de controle. 2019. $169 f$. Dissertação (Mestrado em Direito) - Programa de Pós-Graduação em Direito, Universidade do Vale do Rio dos Sinos - UNISINOS, São Leopoldo, 2019. Disponível em: <http://www.repositorio.jesuita.org.br/bitstream/handle/UNISINOS/8966/Winnie\%20de\%20Campos\%20B ueno_.pdf?sequence=1\&isAllowed=y>. Acesso em: 07 mai. 2020.

CARNEIRO, Aparecida Sueli. A Construção do Outro como Não-Ser como fundamento do Ser. Feusp, 2005.

CASTELLS, Manuel. Redes de indignação e esperança: movimentos sociais na era da internet. Rio de Janeiro: Zahar, 2013.

Zahar, 2003.

A galáxia da internet: reflexões sobre a internet, os negócios e a sociedade. Rio de Janeiro: Jorge . A sociedade em rede. São Paulo: Paz e Terra, 1999.

COLLINS, Patricia Hill. Black feminist thought as oppositional knowledge. Departures in Critical Qualitative
Research,
v.5,
n.3,
p.133-144,
2016.
Disponível
em:

$<$ https://online.ucpress.edu/dcqr/article/5/3/133/81415/Black-Feminist-Thought-as-Oppositional-

Knowledge>. Acesso em: 06 mai. 2020.

COUTINHO, Eduardo Granja (org). Comunicação e contra-hegemonia: processos culturais e comunicacionais de contestação, pressão e resistência. Rio de Janeiro: Editora UFRJ, 2008.

FANON, Frantz. Pele negra, máscaras brancas. Rio de Janeiro: Editora Fator, 1983.

. Pele negra, máscaras brancas. Salvador: EDUFBA, 2008.

LOPES, John Willian. \#VOTELGBT: Ciberativismo por representação política no Brasil. 2018. $236 f$. Dissertação (Mestrado em Estudos da Mídia) - Programa de Pós-graduação em Estudos da Mídia, Universidade Federal do Rio Grande do Norte - UFRN, Natal, 2018.

MANOVICH, Lev. The Language of New Media. Massachusetts: MIT, 2001.

MARTEL, Frédéric. Smart. 0 que você não sabe sobre a internet. Civilização Brasileira, Rio de Janeiro, 2015.

MBEMBE, Achille. Crítica da Razão Negra. Lisboa: Editora Antígona, 2014. 
MOURA, Clóvis. Rebeliões na senzala. Quilombos, insurreições, guerrilhas. São Paulo: Ed. Ciências Humanas, 1981.

Quilombos: resistência ao escravismo. 3. ed. São Paulo: Editora Ática, 1993.

MUNANGA, K. Origem e histórico do quilombo na África. Revista USP, n. 28, p. 56-63, 1996. Disponível em: <http://www.revistas.usp.br/revusp/article/view/28364>. Acesso em: 10 mai. 2020.

NASCIMENTO, Abdias. O Quilombismo: documentos de uma militância pan-africanista. 3ed. São Paulo: Editora Perspectiva, 2019.

O genocídio do negro brasileiro: processo de racismo mascarado. Rio de Janeiro: Editora Paz e Terra, 1978.

NASCIMENTO, Beatriz. O conceito de quilombo e a resistência afro-brasileira. In: NASCIMENTO, Elisa Larkin (org). Cultura em movimento: matrizes africanas e ativismo negro no Brasil. São Paulo: Selo Negro, 2014.

OLIVEIRA, Camila Ken de. Breve introdução ao giro decolonial: poder, saber e ser. II Seminário Científico da Facig - sociedade, ciência e tecnologia. Minas Gerais, nov. 2016. Disponível em: <http://www.pensaracademico.facig.edu.br/index.php/semiariocientifico/article/viewFile/53/38>. Acesso em: 20 abr. 2020.

RIBEIRO, Djamila. Pequeno manual antirracista. São Paulo: Cia das Letras, 2019.

. Quem tem medo do feminismo negro?. São Paulo: Companhia das Letras, 2018.

SILVERSTONE, Roger. Por que estudar a mídia? São Paulo: Edições Loyola, 2002.

SODRÉ, Muniz. A ciência do comum: notas para o método comunicacional. Petrópolis, RJ: Vozes, 2014.

2002.

Antropológica do Espelho: uma teoria da comunicação linear e em rede. Petrópolis, RJ: Vozes,

SOUSA, Neusa Santos. Tornar-se negro: as vicissitudes da identidade do negro brasileiro em ascenção socia. Rio de Janeiro: Edições Graal, 1983.

SOUZA, Jessé. A elite do atraso: da escravidão à Lava Jato. Rio de Janeiro: Leya, 2017.

VELOSO, Maria do Socorro Furtado. Imprensa e contra-hegemonia: 20 anos do Jornal Pessoal (1987-2007). Belém: Paka-Tatu, 2014. 


\section{Resumo}

Propõe-se uma perspectiva metodológica, com base nas raízes históricas de resistência dos quilombos, para análise das mídias negras brasileiras e de suas práticas sociais: o aquilombamento virtual midiático. Trata-se de uma ferramenta que busca intensificar reflexões sobre questões étnico-raciais, na mesma medida em que atua no reforço da identidade negra e de sua agência na sociedade. Essas mídias negras fortalecem a luta antirracista, tendo a comunicação em rede como ferramenta para enfrentar opressões. Partimos do conceito de bios virtual (SODRÉ, 2002), dos quilombos enquanto instituições revolucionárias (B. NASCIMENTO, 1978) e da matriz cognitiva quilombista, centrada na união dos povos negros como organização política-social, e que atualmente ocupa o espaço das redes digitais (A. NASCIMENTO, 2019). Metodologicamente, desenvolvemos pesquisa bibliográfica interdisciplinar, tendo como referência as reflexões de Abdias Nascimento (2019), Djamila Ribeiro (2017, 2018, 2019), Achille Mbembe (2014), Sueli Carneiro (2005), Muniz Sodré (2002), Kabengele Munanga (1996) e Beatriz Nascimento (1978).

Palavras-chave: Mídia. Quilombos. Mídias negras. Aquilombamento virtual midiático.

\section{Abstract}

We propose a methodological perspective based on the historical roots of resistance of the quilombos, for the analysis of black Brazilian media and their social practices: aquilombamento virtual mediatic. It is a approach that aims to intensify reflections on ethnic-racial issues, to the same extent that it works to reinforce black identity and its agency in society. These black media strengthen the anti-racist struggle, using communication in digital media as a tool to face oppression. We start from the concept of virtual bios (SODRÉ, 2002), quilombos as revolutionary institutions (B. NASCIMENTO, 1978) and the quilombist cognitive matrix, centered on the union of black people as a political-social organization, which currently occupies the space of networks (A. NASCIMENTO, 2019). Methodologically, we developed interdisciplinary bibliographic research, having as reference the reflections of Abdias Nascimento (2019), Djamila Ribeiro (2017, 2018, 2019), Achille Mbembe (2014), Sueli Carneiro (2005), Muniz Sodré (2002), Kabengele Munanga (1996) and Beatriz Nascimento (1978).

Keywords: Media. Quilombos. Black media. Aquilombamento virtual mediatic. 


\section{Resumen}

Proponemos una perspectiva metodológica, basada en las raíces históricas de la resistencia de los quilombos, para el análisis de los medios negros brasileños y sus prácticas sociales: aquilombamento virtual mediático. Es un enfoque que busca intensificar las reflexiones sobre cuestiones étnico-raciales, en la misma medida que trabaja para reforzar la identidad negra y su agencia en la sociedad. Estos medios negros fortalecen la lucha antirracista, utilizando la comunicación en red como una herramienta para enfrentar la opresión. Partimos del concepto de bios virtual (SODRÉ, 2002), los quilombos como instituciones revolucionarias (B. NASCIMENTO, 1978) y la matriz cognitiva quilombista, centrada en la unión de los negros como organización político-social, que actualmente ocupa el espacio de las redes. (A. NASCIMENTO, 2019). Metodológicamente, desarrollamos una investigación bibliográfica interdisciplinaria, teniendo como referencia las reflexiones de Abdias Nascimento (2019), Djamila Ribeiro (2017, 2018, 2019), Achille Mbembe (2014), Sueli Carneiro (2005), Muniz Sodré (2002), Kabengele Munanga ( 1996) y Beatriz Nascimento (1978).

Palabras clave: Medios. Quilombos. Medios negros. Aquilombamento virtual mediático.

Este artigo é publicado em acesso aberto (Open Access) sob a licença Creative Commons Attribution Non-Commercial (CC-BY-NC 4.0), que permite que outros remixem, adaptem e criem a partir do seu trabalho para fins não comerciais, e embora os novos trabalhos tenham de lhe atribuir o devido crédito e não possam ser usados para fins comerciais, os usuários não têm de licenciar esses trabalhos derivados sob os mesmos termos. 